\title{
COnE).(OES
}

CIÊNCIA E TECNOLOGIA

\section{EFETIVIDADE DE AÇÕES PRÁTICAS DE EDUCAÇÃO AMBIENTAL PARA O ECOSSISTEMA MANGUEZAL NO ENSINO FUNDAMENTAL}

\author{
Roberto JaCkSON Rodrigues Silva, RAFAEla CAMARgo MAiA ${ }^{1}$ \\ ${ }^{1}$ Instituto Federal do Ceará (IFCE) \\ <sergiorodrigues474@gmail.com><rafaelamaia@ifce.edu.br> \\ DOI: <https://doi.org/10.21439/conexoes.v14i4.1535>
}

\begin{abstract}
Resumo. O manguezal é um ecossistema de importância ecológica e econômica e, apesar de fornecer diversos bens e serviços ambientais, o mesmo vem sofrendo impactos antrópicos negativos. A implantação e consolidação de ações e programas de educação ambiental nas escolas são importantes, uma vez que promove a formação de educandos com saberes críticos e contextualizados. Assim, o presente trabalho tem como objetivo fazer um estudo comparativo de estratégias de ensino teórico e prática para educação ambiental sobre ecossistema manguezal. O trabalho foi desenvolvido com duas turmas do 9 ano de uma escola pública. Foram diagnosticados os conhecimentos prévios dos alunos com um questionário aberto. A seguir, para turma B foi ministrada uma aula teórica sobre o ecossistema e para turma A, uma aula de campo com visitação ao manguezal. E novamente os alunos foram submetidos ao mesmo questionário. Os dados indicam que os alunos apresentaram no questionário prévio, níveis parcialmente satisfatórios de conhecimento sobre o assunto abordado e, após a intervenção, alcançaram níveis satisfatórios. Os resultados obtidos também demonstram que a aula de campo é mais efetiva para aquisição de conhecimentos relativos à conservação do ecossistema para esse público alvo sendo urgente aos agentes de educação a busca de novas formas didáticas, mais participativas, que permitam o protagonismo do aluno.
\end{abstract}

Palavras-chaves: Meio Ambiente. Metodologia de Ensino. Sensibilização ambiental.

\section{EFFECTIVENESS OF PRACTICAL ACTIONS OF ENVIRONMENTAL EDUCATION FOR THE MANGROVE ECOSYSTEM IN FUNDAMENTAL EDUCATION}

\begin{abstract}
The mangrove is an ecosystem of ecological and economic importance and, despite providing several environmental goods and services, it has suffered negative anthropic impacts. The implementation and consolidation of actions and programs of environmental education in schools are important, since it promotes the formation of students with critical and contextualized knowledge. Thus, the objective of this paper was to realize a comparative study of theoretical and practical teaching strategies for environmental education on mangrove ecosystem. The work was developed with two classes of the 9th grade of a public school. Prior knowledge of the students was diagnosed with an open questionnaire. Next, for class B, a theoretical class was given on the ecosystem and for class A, a field class with a visit to the mangrove. And again the students were submitted to the same questionnaire. The data indicate that the students presented in the previous questionnaire, partially satisfactory levels of knowledge about the subject addressed and, after the intervention, reached satisfactory levels. The results obtained demonstrate that the field class is more effective for acquiring knowledge regarding the conservation of the ecosystem for this target audience, and it is urgent for the education agents to search for new didactic forms, more participatory, that allow the protagonism of the student.
\end{abstract}

Keywords: Environmental. Study methodology. Environmental awareness

\section{INTRODUÇÃO}

O manguezal é o ecossistema florestal característico de regiões costeiras tropicais de todo mundo (TOMLINSON, 2016). Segundo Lee et al. (2014), apresentam diversas funções naturais, sendo áreas de alimentação, abrigo e reprodução para muitas espécies endêmicas, estreitamente ligadas ao sistema, visitantes e migratórias. Dessa forma, os manguezais atuam como importantes mantenedores da diversidade biológica, inclu- sive de espécies de interesse econômico (MAIA, 2016). Várias famílias tradicionais sobrevivem dos recursos extraídos desse ecossistema, podendo-se destacar os catadores de caranguejos ou caranguejeiros e, ainda, as marisqueiras.

Entretanto, apesar da sua grande importância ecológica, os manguezais vêm sofrendo um intenso processo de destruição ao longo do litoral brasileiro com irreparáveis prejuízos ambientais (REZENDE et al., 2015). 
Alguns processos, de origem antrópica, que provocam alterações neste ambiente são a retirada da madeira, agricultura e a carcinicultura. Contudo, também podemos citar a expansão urbana e um mau planejamento do uso do solo, o estabelecimento de complexos portuários, a construção de pólos industriais, a instalação hoteleira inadequada assim como de salinas, a exploração da madeira para lenha e carvão, a disposição inadequada de resíduos e a pesca predatória (PINHEIRO; TALAMONI, 2018).

Da importância que já foi abordada e dos impactos ambientais listados, o manguezal se torna um ambiente ideal para o exercício da educação ambiental. Entretanto, a falta de conhecimento sobre a importância desse ecossistema é uma das maiores dificuldades para sua preservação e conservação (ALBUQUERQUE; FARIAS; MAIA 2015). Por esse motivo, várias ações de educação ambiental no Brasil têm como principal objetivo sensibilizar populações para a problemática da poluição, desmatamento e ocupação desordenada no manguezal (PINHEIRO; TALAMONI, 2018).

Para um trabalho de educação ambiental eficaz, investimentos em estudos de percepção ambiental são essenciais, pois por meio destes é possível analisar os conhecimentos prévios dos alunos e a forma como possivelmente vem sendo desenvolvida a consciência ambiental sobre o manguezal. Dessa forma, busca desenvolver nos educandos atitudes que objetivam a conservação, promovendo o conhecimento sobre a sua importância. Assim, para garantir a sobrevivência dos manguezais é preciso uma nova visão de conservação, promovendo uma educação ambiental holística e que permita realizar uma mudança na prática social (JACOBI 2003).

Nesse contexto, o presente trabalho teve como objetivo geral desenvolver uma intervenção educacional ambiental sobre a conservação dos manguezais, por meio de aulas práticas e teóricas, mostrando a importância da fauna e da flora para discentes do ensino fundamental público. E especificamente; 1) diagnosticar o conhecimento prévio dos alunos, sobre o manguezal e; 2) realizar um estudo comparativo de estratégias de ensino teórica e prática para educação ambiental nesse ecossistema.

\section{FUNDAMENTAÇÃO TEÓRICA}

Os manguezais são constituídos por espécies vegetais lenhosas típicas (angiospermas), além de macro e microalgas, adaptadas as variações de salinidade e um substrato com pouco oxigênio dissolvido (TOMLINSON, 2016). Apresentam maior desenvolvimento em climas tropicais e subtropicais, ou seja, nas faixas

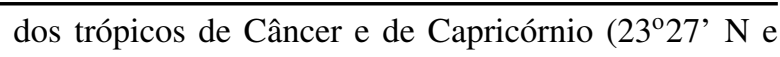
$23^{\circ} 27^{\prime} \mathrm{S}$ ) com desenvolvimento estrutural máximo próximo a linha do Equador (DUKE, 2017). Dos 7.408 $\mathrm{km}$ de extensão da costa brasileira, 6.786 km são formados por manguezais (LEãO; PRATES; MATTEO. 2018). No Brasil, desde o Amapá, os manguezais são encontrados ao longo de todo o litoral até a cidade de Laguna (2830'S), em Santa Catarina, limite sul desse ecossistema no Oceano Atlântico (VALE; SCHAEERNOVELLI, 2018).

Apresenta-se como um ambiente de grande importância socioambiental. Sua importância social dar-se pelo fato de que muitas pessoas vivem da pesca e do aproveitamento de produtos extraídos do manguezal, uma forma de complementação parcial ou total da renda familiar (PINHEIRO; TALAMONI, 2018). E a importância ambiental provém da sustentação da cadeia trófica costeira, sendo fonte de detritos para águas adjacentes, servindo como área de refúgio, alimentação e reprodução para muitas espécies animais, incluindo as de valor econômico (MAIA, 2016). Cabe destacar, que a vegetação de mangue protege o litoral das grandes marés e funciona como mata ciliar nos estuários atuando de forma direta para diminuir ou conter processos erosivos de assoreamento (LEE et al. 2014). Essa flora apresenta características morfológicas e fisiológicas adaptativas, como raízes aéreas, propágulos dispersos pelas marés, uma copa que alcança um rápido crescimento, ausência de anéis de crescimento nos troncos, um eficiente mecanismo de retenção de nutrientes e água e ainda glândulas excretoras de sal nas folhas (TOMLINSON, 2016; DUKE, 2017).

A fauna deriva de três pontos principais, dos ambientes marinho, dulcícola e terrestre adjacentes. Esses organismos apresentam uma série de adaptações que possibilitam explorar esse ambiente desde o solo até a copa das árvores, migrando com o fluxo de maré e escavando os substratos. As espécies que possuem maior destaque, considerando riqueza de espécies, abundância de organismos e diversidade biológica, são aves, peixes, crustáceos e moluscos (MAIA, 2016).

No Brasil, esses ecossistemas são protegidos pelo Código Florestal (Lei no 12.651/2012), que reconhece o manguezal em toda a sua extensão como Área de Preservação Permanente (APP) (BRASIL, 2012). Entretanto, a execução das medidas protetivas tem se demostrado ineficientes, desta maneira, tornando os ecossistemas de manguezais vulneráveis e frágeis com o avanço dos impactos antrópicos. Segundo Lee et al. (2014), os impactos causados pelo desmatamento do mangue podem causar fuga ou morte da fauna associada, lixiviação, retirada de nutrientes pela água e uma erosão 
gradativa, influenciando a distribuição e abundância da fauna e a produtividade do ecossistema.

Outro problema são os resíduos sólidos. Os manguezais estão próximos de terminais portuários ou no centro das cidades, funcionando como depósito de uma quantidade significativa de resíduos (SOUZA, 2016). A disposição de resíduos, em escalas superiores as suportadas pelo ambiente, decorrente da crescente ocupação humana, gera efluentes que nem sempre são assimilados pelo ecossistema. Portanto, a disposição desses materiais tóxicos consiste em uma ameaça global devido à persistência de seus componentes no ecossistema.

No trabalho realizado por Paula, Lima e Maia (2016), a área de manguezal no estuário do Rio Acaraú, encontra-se em um estágio crítico quanto à degradação e descaracterização da paisagem. Em todas as amostras analisadas constatou-se a ocorrência de troncos cortados ou árvores mortas resultantes do desmatamento, da disposição de resíduos sólidos ou a carcinicultura. Esses impactos provocam diretamente uma alteração na produtividade natural do ecossistema, além de modificações socioeconômicas, já que força a saída de populações locais devido à redução dos estoques pesqueiros (FRAGOSO, 2011).

Uma das maneiras para diminuir as ações impactantes sobre o ecossistema manguezal é a realização de programas de educação ambiental que promovam a sustentabilidade. Segundo a Política Nacional de Educação Ambiental (Lei n ${ }^{\circ}$ 9795/1999, Art $1^{\circ}$ ).

\footnotetext{
"Entende-se por educação ambiental "os processos por meio dos quais o indivíduo e a coletividade constroem valores sociais, conhecimentos, habilidades, atitudes e competências voltadas para a conservação do meio ambiente, bem de uso comum do povo, essencial à sadia qualidade de vida e sua sustentabilidade" (BRASIL 1999. p. 2)
}

Assim, diversos trabalhos vêm sendo realizados de forma a levantar conhecimentos prévios sobre a ecologia de ecossistemas, entre eles, os manguezais, no ambiente escolar. Por exemplo, Rodrigues e Farrapeira (2008) Rodrigues e Farrapeira (2008) realizaram um trabalho em uma escola pública de Recife envolvendo os manguezais. Farias e Andrade (2010) desenvolveram um estudo com os manguezais de Sergipe com alunos de escolas públicas e privadas. E Albuquerque (2016) trabalhou com a percepção ambiental de crianças da educação básica no ensino público do Ceará. Nesse contexto, a educação ambiental tem uma função primordial no entendimento da dinâmica ecossistêmica levando a uma maior consciência de preservação desses ambientes (SATO; SANTOS, 2001).

\section{METODOLOGIA}

\section{1 Área de estudo}

O presente estudo foi realizado em Acaraú, no Ceará, aproximadamente $290 \mathrm{~km}$ da capital do estado, Fortaleza. O município está situado na zona litorânea da Região Extremo Oeste do Estado, se estendendo em uma área territorial de $842,559 \mathrm{~km}^{2}$ com uma população de 62.199 habitantes (IBGE, 2017). Possui clima Tropical Quente Semiárido Brando predominante e com vegetação constituída por um Complexo Vegetacional da Zona Litorânea, Floresta Mista DicotilloPalmácea e Floresta Perenifólia Paludosa Marítima (IPCE, 2016). Segundo a Prefeitura Municipal de Acaraú, a cidade possui sua economia baseada em atividades de pesca, agricultura e agropecuária. Nos últimos anos, merece destaque a implantação de parques eólicos e o cultivo de camarão em cativeiro (SOUSA, 2017).

Este estudo foi desenvolvido de uma Escola de Ensino Fundamental Pública em Acaraú. Inicialmente, foram realizadas conversas informais com a gestão da escola para uma autorização prévia ao estudo. Após a aprovação, no que diz respeito à disponibilidade da instituição, dos docentes e discentes para realização da pesquisa foram selecionadas duas turmas com mesmo nível de aprendizagem, que tivessem os mesmos professores e mesmo turno de aulas.

Assim, foram selecionadas duas turmas de $9^{\circ}$ ano (A e B). A amostra foi composta por 32 alunos, sendo no $9^{\circ} \mathrm{A}, 15$ alunos, e no $9^{\circ} \mathrm{B}, 17$ alunos. A escola fica próximo ao estuário do rio Acaraú, e muitas famílias que residem nessa região vivem dos recursos extraídos dos manguezais como, crustáceos, moluscos e peixes complementando sua renda familiar mensal (observação pessoal).

\subsection{Metodologia}

Primeiro, a fim de se conhecer a percepção dos alunos foi utilizado um questionário de 08 questões com características gerais, importância, flora e fauna dos manguezais. O presente instrumento foi aplicado nas duas turmas antes da intervenção e os alunos tiverem 30 minutos para resolução. A seguir, para turma do $9^{\circ} \mathrm{B}$ foi ministrada uma palestra, na forma de uma aula teórica com 40 minutos de duração, a qual abordava fauna e flora dos manguezais, além de impactos e medidas de conservações.

Para turma do $9^{\circ} \mathrm{A}$ foi ministrada uma aula de campo (prática). Os alunos foram levados para o manguezal no estuário do rio Acaraú e, por 40 minutos observaram a fauna e a flora que compõem o ecossistema. Foram repassadas aos alunos as mesmas informações 
da palestra descrita acima, porém in situ à medida que observavam cada componente.

\subsection{Análise de dados}

Para analisar os dados coletados nesta pesquisa, foram utilizadas as metodologias propostas por Rodrigues e Farrapeira (2008) e Vairo e Rezende Filho (2010) que classifica as respostas obtidas nos seus questionários em três categorias: "Satisfatória", para as respostas completas nas quais os alunos demonstraram ter um conhecimento significativo do assunto; "Parcialmente Satisfatória", para aquelas onde os alunos demonstraram ter um conhecimento mínimo a razoável (mas incompleto) do assunto abordado; e "Insatisfatórias", no caso dos alunos que demonstraram ou declararam nada saber sobre o assunto, ou ainda, quando os mesmos deixaram as questões em branco. Posteriormente, foram realizadas comparações quanto aos números de respostas obtidas dentre as aulas teóricas e práticas por meio de planilhas eletrônicas e gráficos.

\section{RESULTADOS E DISCUSSÃO}

Os dados obtidos no presente trabalho indicam que o público alvo apresentou um nível parcialmente satisfatório de conhecimento sobre os manguezais enquanto após a intervenção obtiveram resultados satisfatórios.

A primeira questão que versava a definição dos manguezais (Figura 1) teve como finalidade analisar qual a percepção dos alunos sobre o ecossistema, se os mesmos sabiam definir o que seria em poucas palavras ou o que eles imaginavam sobre a temática. Foram consideradas satisfatórias respostas que continham acima de três exemplos do ecossistema estudado como um local, ecossistema, ambiente, lugar que apresenta lama, plantas, raízes submersas e presença de animais.

As respostas para essa questão foram principalmente insatisfatórias (Figura 1) nos questionários prévios nas duas turmas analisadas com $45 \%$ e $57 \%$ respectivamente, $9^{\circ} \mathrm{A}$ e B. Pode-se observar que a frequência de resultados satisfatórios aumentou enquanto diminuíram as respostas insatisfatórias após as intervenções. $\mathrm{Na}$ vivência da aula de campo observou-se um resultado elevado quando comparado a aula teórica, sendo $60 \%$ responderam satisfatoriamente após a intervenção da aula de campo e $18 \%$ depois da aula teórica. Esses contrastes podem estar ligados à rotina de aulas teóricas sem a retirada desses alunos do modelo tecnicista. Segundo Martins (2009), o professor que opte em mudar o tradicionalismo da aula expositiva deve buscar meios que promovam o protagonismo dos discentes, que dessa forma, estarão envolvidos e empenhados no próprio processo de aprendizagem, sendo um exemplo, aulas práticas ou de campo.

$\mathrm{Na}$ segunda questão, esperava-se que os alunos mencionassem que o manguezal retrata todo o ecossistema enquanto "mangue" está relacionado as árvores que o compõe (SCHAEFFER-NOVELLI, 2012). Com as respostas obtidas nesta questão (Figura 2), os alunos mostraram não conhecer a diferença entre os dois termos, e isso foi demonstrado no questionário prévio nas duas turmas, com $76 \%$ e $75 \%$ de respostas insatisfatórias. Ocorrendo de as mesmas alcançarem valores iguais para a categoria satisfatória, ainda no questionário prévio, com 9

Após as ações de intervenção, esses resultados tiveram um saldo positivo. A turma A obteve apenas $7 \%$ de respostas insatisfatórias e a turma $\mathrm{B}$ não teve respostas insatisfatórias. Esse resultado se torna relevante quando comparado com os questionários prévios. Cabe ressaltar que que $46 \%$ dos alunos da aula de campo responderam satisfatoriamente, afirmando que há uma diferença entre esses dois conceitos e, $41 \%$ dos alunos da aula teórica souberam diferenciar satisfatoriamente.

Quanto à questão sobre as características dos manguezais (Figura 3), as respostas no questionário prévio foram em sua maioria insatisfatórias para as duas turmas, com $86 \%$ e $88 \%$ de frequência e, apenas $5 \%$ de respostas satisfatórias para turma A e, nenhuma para turma B. Os alunos caracterizaram o ocossistema apenas como um local onde ocorre o encontro "da águas do rio com a do mar" e que sofrem "influência da maré", sem caracterizar sua composição biológica (Tabela 1).

Esta pergunta continha um grau de dificuldade maior, sendo que as respostas deveriam mencionar, segundo (SCHAEFFER-NOVELLI, 2012), que os manguezais estão localizados nas regiões tropicais, sob a influência de marés, com sedimento pouco incosolidado e com uma baixa concentração de oxigênio dissolvido. Cabe ressaltar que antes da aula teórica e de campo, os resultados satisfatórios eram baixos e após a intervenção, a frequência de respostas satisfatórias e parcialmente satisfatórias aumentaram, para $20 \%$ e $67 \%$ na aula de campo e, $30 \%$ e $35 \%$ na aula teórica, respectivamente. Apenas $13 \%$ dos alunos mantiveram respostas insatisfatórias na aula de campo e $35 \%$ após a aula teórica.

Em relação à diferença entre os mangues e as plantas terrestres (Figura 4), as respostas foram insatisfatórias para as duas turmas trabalhadas no questionário previo, como mostra a figura 4 , com $49 \%$ e $56 \%$ para insatisfatória e $47 \%$ e $38 \%$ parcialmente satisfatória e apenas $4 \%$ e $6 \%$ satisfatória, para as turmas A e B, respectivamente. Esses resultados expressam que os alu- 


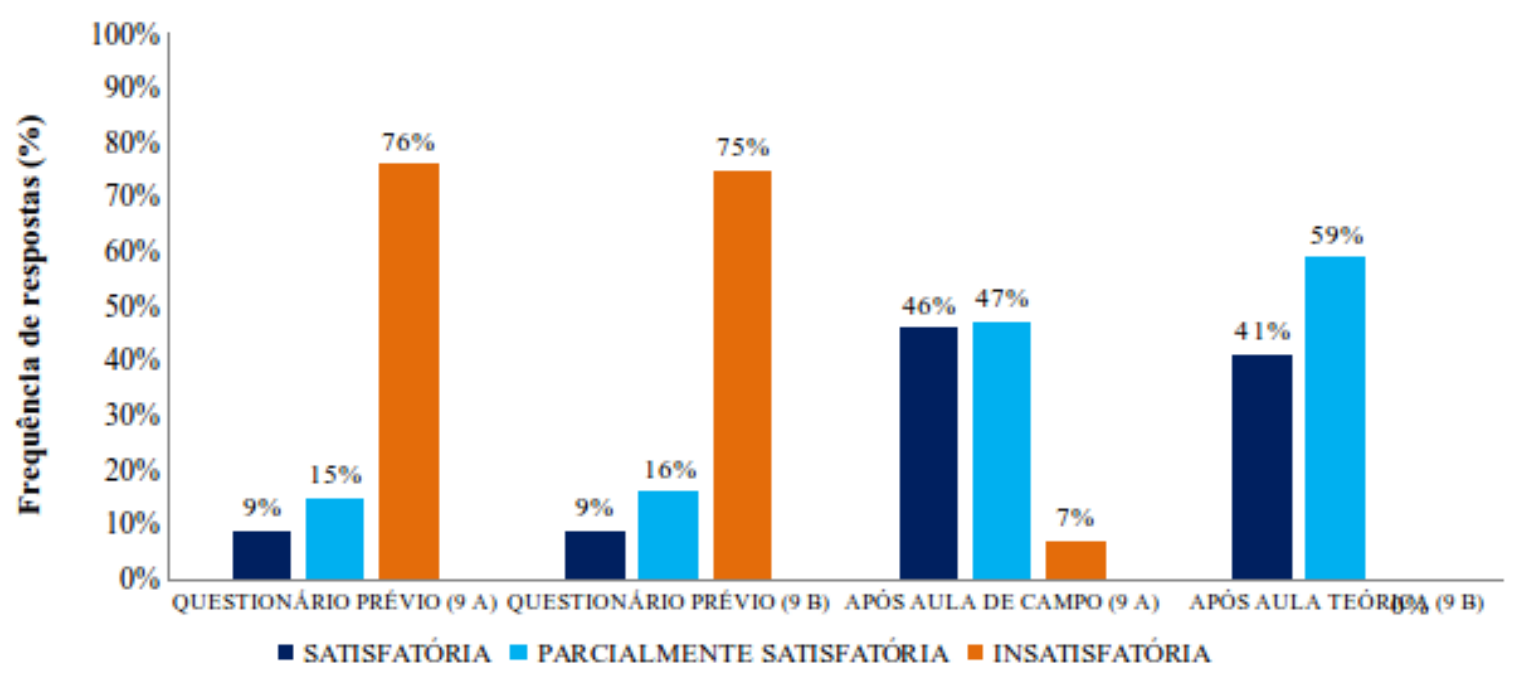

Figura 1: Frequência de respostas (\%) dos alunos referente a pergunta 01: Defina manguezal. Classificando-as quanto às categorias satisfatória, parcialmente satisfatória e insatisfatória, referente às ações efetivas que foram submetidos (questionário prévio, aula de campo e aula teórica). Fonte: Autores.

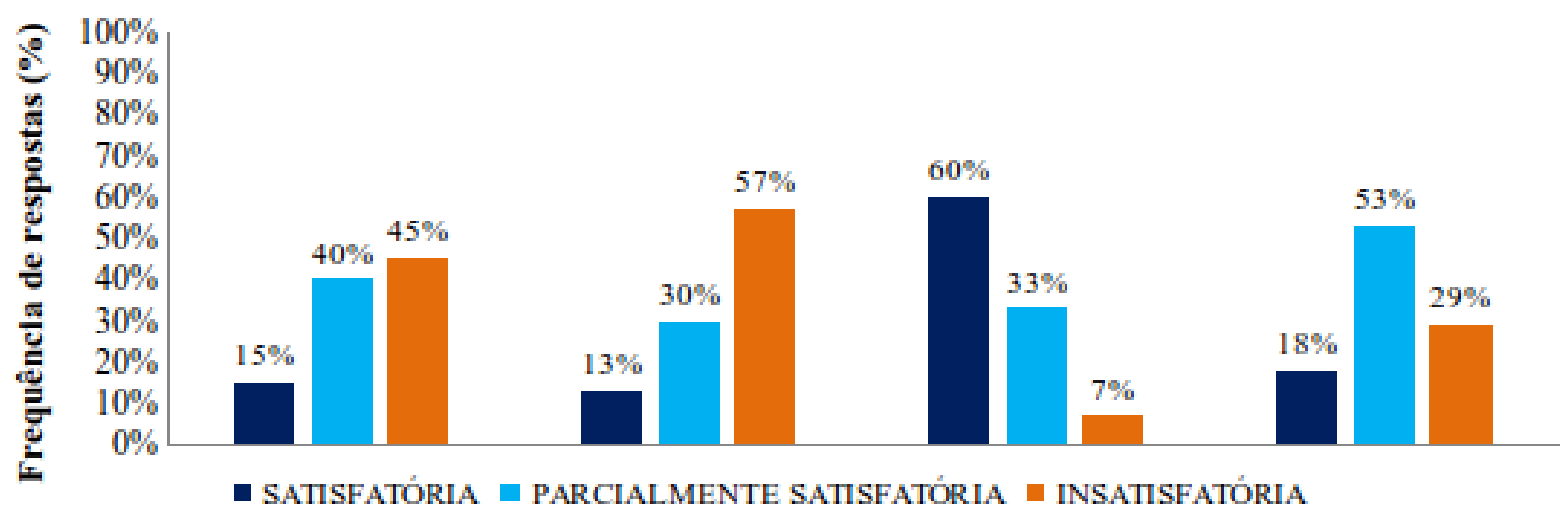

Figura 2: Frequência de respostas $(\%)$ dos alunos, referente à pergunta 02: Diferencie manguezal de mangue. Classificando-as quanto às categorias satisfatória, parcialmente satisfatória e insatisfatória, referente às ações efetivas que foram submetidos (questionário prévio, aula de campo e aula teórica).

Fonte: Autores. 


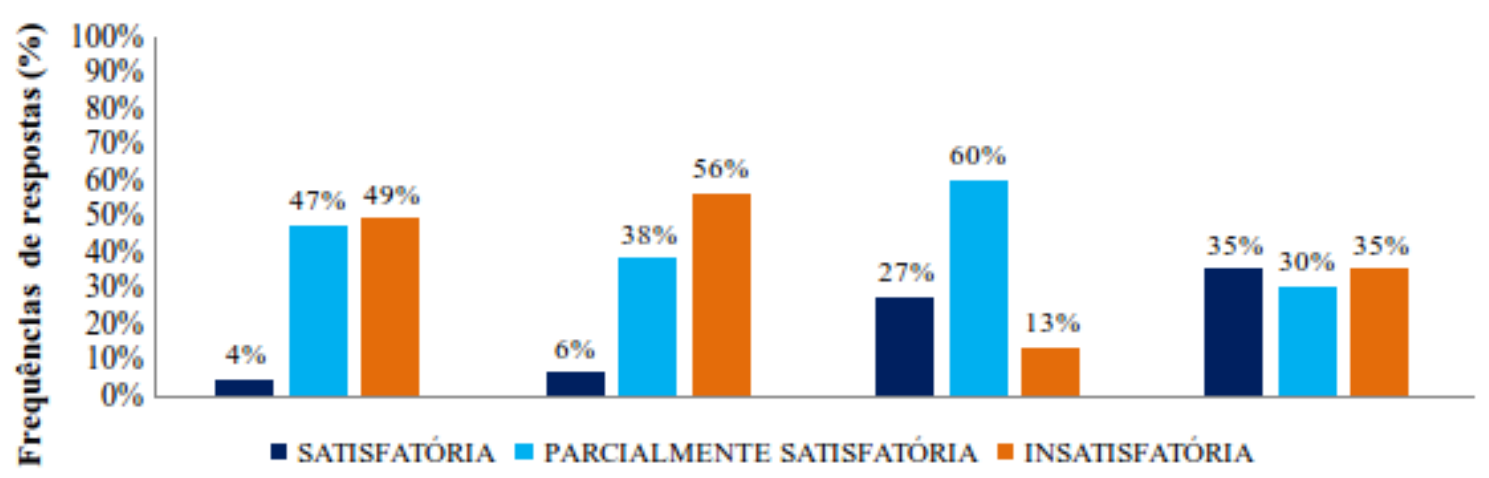

Figura 3: Frequência de respostas (\%) dos alunos, referente à pergunta 03: Quais as características do ecossistema manguezal? Classificandoas quanto às categorias satisfatória, parcialmente satisfatória e insatisfatória, referente às ações efetivas que foram submetidos (questionário prévio, aula de campo e aula teórica).

Fonte: Autores.

Tabela 1: Cognição comparada referente às características do ecossistema manguezal para os alunos submetidos à aula prática e teórica.

\begin{tabular}{|c|c|}
\hline Citação dos alunos & Citação da literatura \\
\hline \multicolumn{2}{|c|}{ Alunos submetidos a aula prática } \\
\hline $\begin{array}{c}\text { "O solo dele é com pouco oxigênio e as plantas } \\
\text { tiveram que passar por uma adaptação para } \\
\text { conseguirem se desenvolver". }\end{array}$ & $\begin{array}{l}\text { "O solo contém uma baixa concentração de oxigênio } \\
\text { dissolvido e as adaptações fisiológicas e morfológicas na } \\
\text { vegetação se fizeram necessárias para uma melhor } \\
\text { sobrevivência nesse ambiente" } \\
\text { (SCHAEFFER-NOVELLI, 2012). }\end{array}$ \\
\hline $\begin{array}{l}\text { "Nas folhas tem uma coisa para colocar } \\
\text { o sal pra fora". }\end{array}$ & $\begin{array}{l}\text { "As folhas possui um pecíolo vermelho e nele contendo } \\
\text { duas glândulas excretoras de sal"(MAIA, 2016). }\end{array}$ \\
\hline \multicolumn{2}{|c|}{ Alunos submetidos a aula teórica } \\
\hline "Temperatura igual ou superior a $20^{\circ} \mathrm{C} "$. & $\begin{array}{l}\text { "Esse ecossistema se encontra onde a temperatura } \\
\text { é igual ou superior a } 20^{\circ} \mathrm{C} "(\text { DUKE, 2017). }\end{array}$ \\
\hline "Típico de regiões tropicais e subtropicais". & $\begin{array}{l}\text { "Ecosistema característico de regiões costeiras } \\
\text { tropicais de todo mundo"(TOMLINSON 2016). }\end{array}$ \\
\hline
\end{tabular}

Fonte: Autor. 
nos deteram-se apenas na capacidade dos mangues de viverem na lama (devido sua forma radicular), não citando outras características.

Após a intervenção, os resultados passaram de insatisfatório para parcialmente satisfatório. A aula de campo demonstrou uma eficácia maior, com $60 \%$ de respostas parcialmente satisfatórias, comparada aos $30 \%$ da aula teórica. Os valores satisfatórios ficaram em $27 \%$ para a aula de campo e $35 \%$ para a aula teórica.

No manguezal, a flora que faz a composição desse ecossistema possui uma baixa diversidade. Foram registradas cinco espécies no Ceará em estudo feito por Maia e Coutinho (2012), sendo elas, Rhizophora mangle L., Avicennia germinans (L.) Stearn., Avicennia schaueriana Stapft Leechm, Laguncularia racemosa R. (Gaertn) e Conocarpus erectus. Ao modo que as adaptações morfológicas e fisiológicas que estas árvores tiveram que passar para se manterem estáveis neste ambiente funcional e estruturalmente único incluem raízes aéreas e de sustentação, glândulas excretoras de sal nas folhas, estratégias de exclusão e compartimentalização de sais e viviparidade de seus propágulos tornandoos mais resistentes e aumentando as chances de sua fixação (DUKE, 2017).

Com relação a esse aspecto, o conhecimento dos alunos no questionário prévio era pouco ou nenhum. Após a intervenção e principalmente após a aula de campo, os alunos mostraram um resultado de parcialmente satisfatório a satisfatório. Na aula teórica, as três categorias de avaliação demostraram resultados semelhantes, novamente mostrando que uma aula de campo bem planejada obtém efeito, uma vez que aproxima o aluno com a prática trabalhista ou com a realidade a sua volta, corroborando com os dados de Machado (2003).

Quando pedidos para listar os animais característicos do ambiente (Figura 5), todos os alunos entrevistados, tanto no questionário prévio quanto após as ações não mencionaram nenhum animal terrestre ou característico de outro ecossistema, apenas os que habitavam nos manguezais. Dessa forma, os resultados da quinta questão indicaram que $70 \%$ e $63 \%$ dos alunos das turmas A e B, no questionário prévio, sabiam informar satisfatoriamente sobres esses animais. Citando três ou mais animais presentes no manguezal. E ainda nesse questionário, as turmas responderam de forma parcialmente satisfatória em $20 \%$ e $31 \%$ dos casos e obtiveram valores baixos para a categoria insatisfatória, com $10 \%$ e $6 \%$. Cabe ressaltar que as duas turmas tinham um grande conhecimento prévio a respeito da fauna dos manguezais, porém, após a aula de campo foi observado um aumento relativo das respostas satisfatórias de $25 \%$ quando comparado a aula teórica, com 17\%. Após as ações de intervenção, as duas turmas não tiveram respostas insatisfatórias.

Nessa questão, as intervenções sugiram efeito semelhante e isso implica na forma como o educador transmitiu o conhecimento para os educandos e ao fato dos alunos terem no seu cotidiano esses animais, muitos sendo comercializados por eles ou sua família uma vez que moram nas regiões circunvizinhas aos manguezais da região. Entre os animais citados estão siris, caranguejos, búzios, sururu, ostras e maria-farinhas, nomes populares de espécies Callinectes spp., Ucides cordatus (Linnaeus, 1763), Anomalocardia brasiliana (Linnaeus, 1767), Mytella spp., Crassostrea rhizophora (Guilding, 1828) e Goniopsis cruentata (Latreille, 1803), respectivamente, comuns em manguezais e exploradas comercialmente no Ceará (MAIA, 2016).

No que diz respeito a esta questão de comercialização dos produtos advindos dos manguezais (Figura 6), os alunos tiveram um pouco de dificuldade, o que refletiu nos resultados das ações a que foram submetidos. As duas turmas ao responderem o questionário prévio não tiveram um resultado positivo. Os resultados satisfatórios foram baixos, de $15 \%$ e $6 \%$ para as turmas A e $\mathrm{B}$, respectivemente. As respostas insatisfatóriass foram altas, com $43 \%$ para a turma A e, com um valor maior para a turma B, de $56 \%$. Os resultados parcialmente satisfatórios foram semelhantes nas duas turmas.

Após a aula teórica, os alunos mantiveram os $6 \%$ que tiveram no questionário prévio de resultado satisfatório, enquanto na aula de campo, os alunos obtiveram $34 \%$ de respostas satisfatórias. Essas diferenças devemse ao fato dos alunos terem ido a campo e terem visto na prática esses animais de valor econômico, dando uma ênfase para a importância da conservação e os períodos de defeso, como é o caso do caranguejo Uçá, Ucides cordatus. Quanto a categoria insatisfatória, a turma que teve a aula teórica manteve os $56 \%$ do questionário prévio, enquanto a sala que foi à campo, teve a porcentagem obtida no questionário prévio diminuida a $10 \%$, portanto, ficando com um insatisfatório de $33 \%$.

Um fato importante na questão 07 (Figura 7) é que ao se referirem aos principais motivos que ameaçam os manguezais, a maioria dos alunos citou uma variedade de causas presentes e que o principal responsável por essas ameaças é o homem. Dentre as respostas citadas temos o desmatamento, poluição, queimadas, pesca predatória e fazendas de carcinicultura corroborando com a literatura específica ao tema para a costa oeste do litoral cearense como observado por (THIERS; MEIRELES; SANTOS, 2016).

No questionário prévio, os alunos tinham um conhecimento a respeitos dos impactos parcialmente satisfa- 


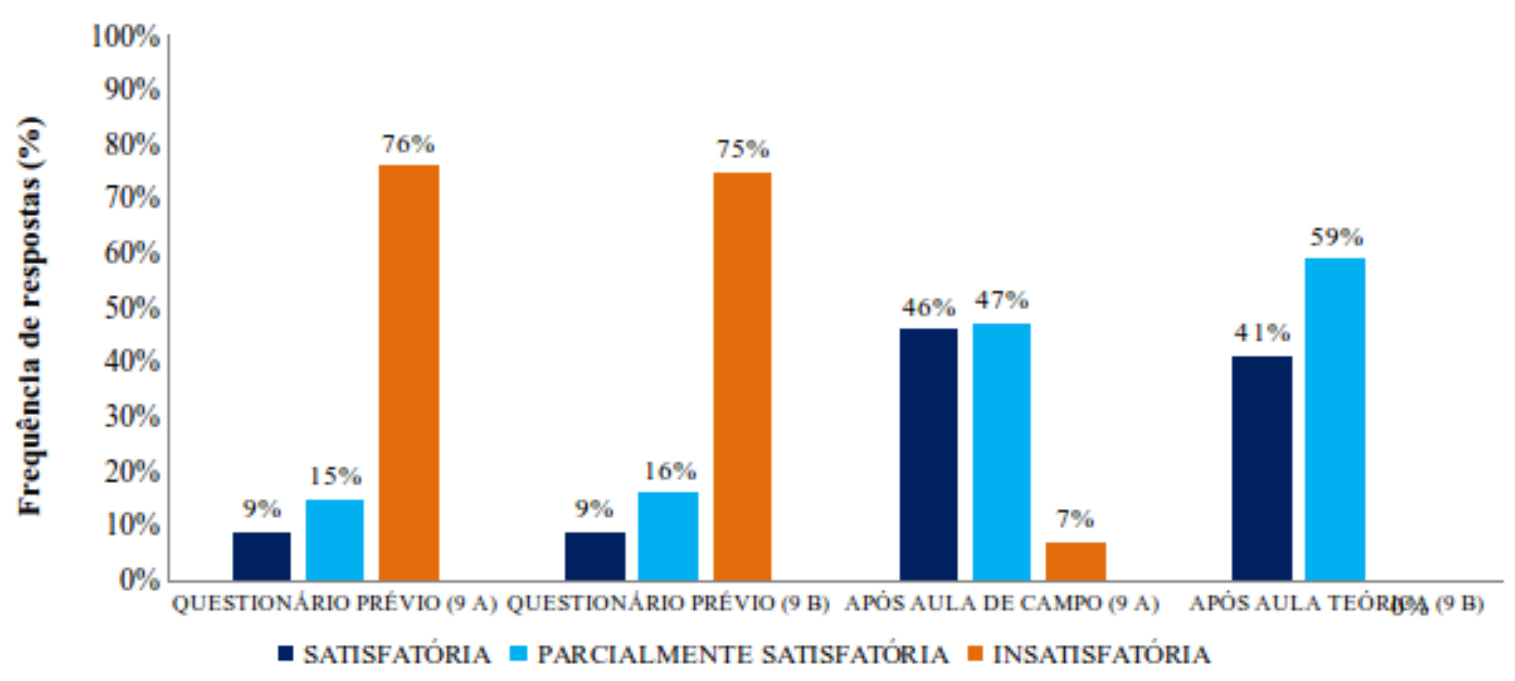

Figura 4: Frequência de respostas (\%) dos alunos, referente à pergunta 04: Quais as diferenças das plantas de mangues e das terrestres? Classificando-as quanto às categorias satisfatória, parcialmente satisfatória e insatisfatória, referente às ações efetivas que foram submetidos (questionário prévio, aula de campo e aula teórica). Fonte: Autores.

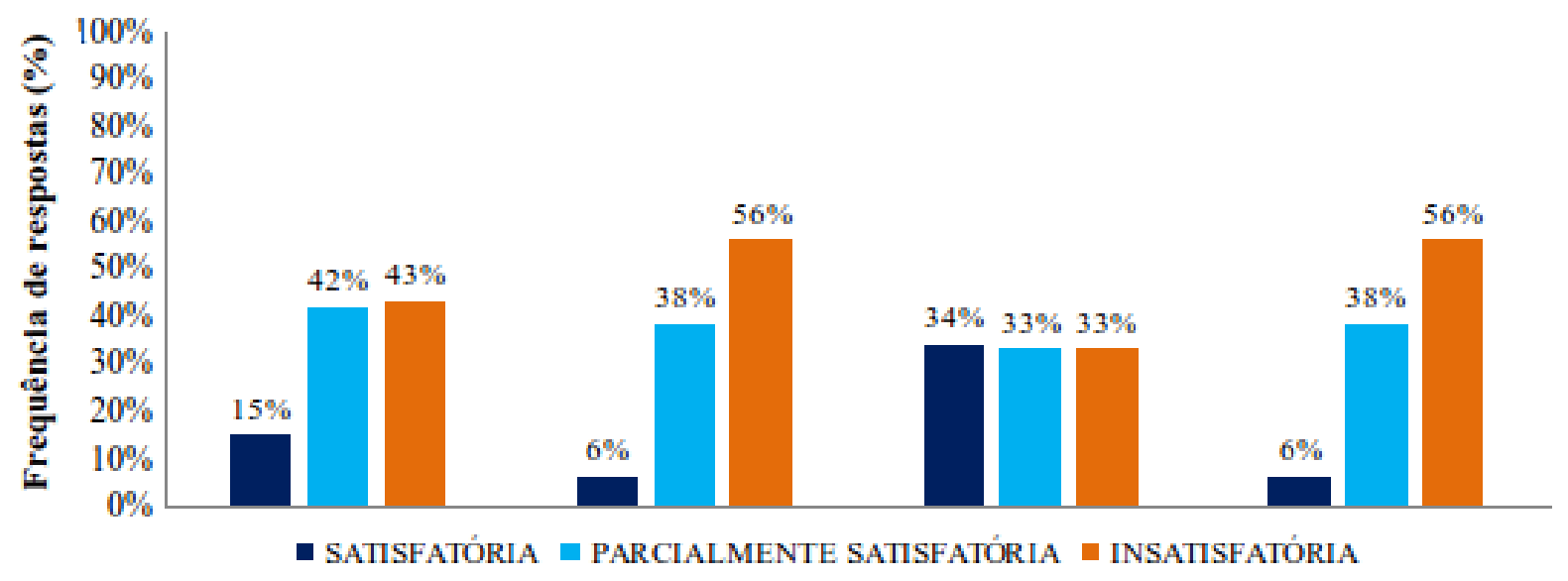

Figura 5: Frequência de respostas (\%) dos alunos, referente à pergunta 05: Que animais vivem no manguezal? Classificando-as quanto às categorias satisfatória, parcialmente satisfatória e insatisfatória, referente às ações efetivas que foram submetidos (questionário prévio, aula de campo e aula teórica).

Fonte: Autores. 


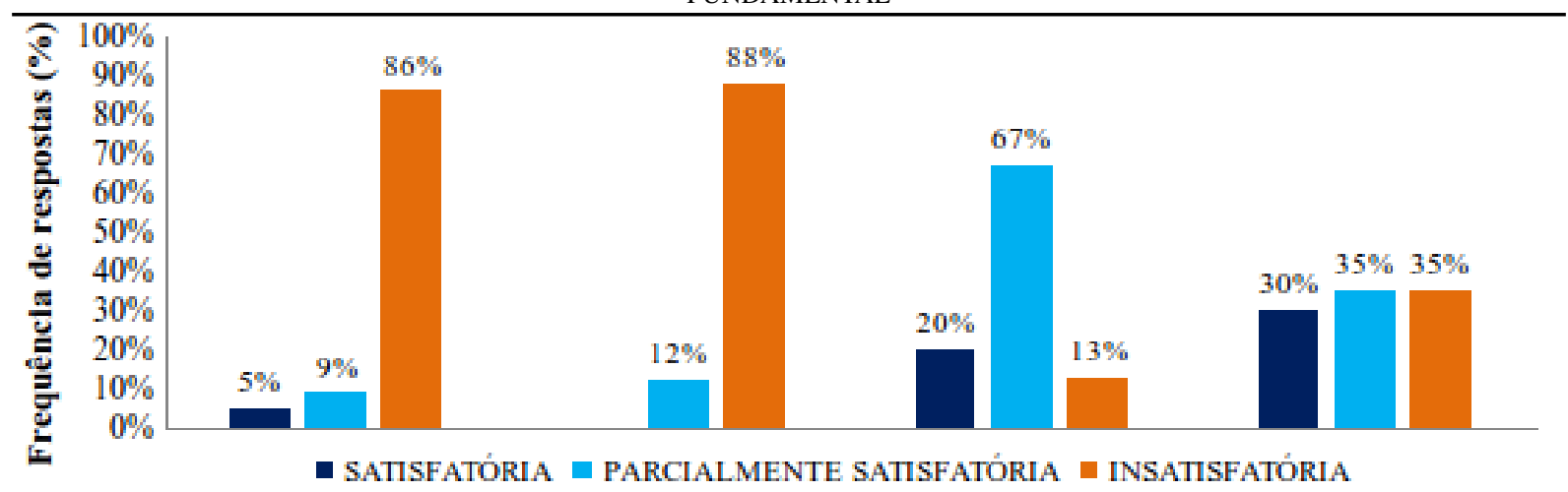

Figura 6: Frequência de respostas $(\%)$ dos alunos, referente à pergunta 06: Do que existe no manguezal, o que pode ser utilizado comercialmente? Classificando-as quanto às categorias satisfatória, parcialmente satisfatória e insatisfatória, referente às ações efetivas que foram submetidos (questionário prévio, aula de campo e aula teórica).

Fonte: Autores.

tório. A turma B mostrando valores maiores em relação a turma A na categoria satisfatória e parcialmente satisfatória. Na categoria insatisfatória, a tuma A obteve $43 \%$ e a turma B, $28 \%$, significando que a turma B apresentou um maior conhecimento a respeito dos impactos que os manguezais sofrem em relação a turma $\mathrm{A}$, no questionário prévio.

Todavia, após as ações de intervenção, as duas turmas tiveram um desempenho satisfatório, mostrando um interesse na conservação deste ecossistema. A turma A que teve a aula de campo obteve $73 \%$ das respostas satisfatórias, $20 \%$ de parcialmente satisfatórias e $7 \%$ de insatisfatórias, enquanto a turma $\mathrm{B}$, que tiveram a aula teórica, obtiveram $88 \%$ de respostas satisfatórias, $12 \%$ de parcialmente satisfatória e nenhuma resposta insatisfatória.

Todos os alunos consideram os manguezais de extrema importância (Figura 8), entretanto, no ponto em que era necessário justificar a resposta, não souberam explicar. Assim, foi observado um resultado insatisfatório no questionário prévio de $40 \%$ na turma A e de $57 \%$ na turma B. As respostas que foram consideradas satisfatórias para as duas turmas e os valores de porcentagens foram baixos, $15 \%$ e $13 \%$. Com a realização das ações de intervenção, os alunos conseguiram relatar a importância do ecossistema e obteve-se um resultado da aula de campo com $60 \%$ de respostas satisfatórias quando comparado à aula teórica, com $18 \%$, mostrando que o uso de um ambiente natural pode ser um recurso didático importante. Sobre as respostas insatisfatórias, a aula de campo teve $7 \%$, um valor importante quando comparado com o questionário prévio que era de $40 \%$. Em contrapartida, a aula teórica teve $29 \%$ de respostas insatisfatórias após a intervenção e no questionário prévio o valor ficou em 57\%, mostrando que as aulas práticas se tornam cada vez mais importante e devem ser adotadas pelos professores.

Os resultados apresentados neste trabalho indicam que aulas de campo constituem-se em uma oportunidade para o desenvolvimento de vínculos afetivos entre os alunos, o ecossistema e os seres vivos, uma vez que leva a observação e reconhecimento das espécies de animais, de seus hábitos e suas relações ecológicas. Para Farrapeira e Pinto (2005), aulas no ambiente natural se adequam a vários níveis escolares e metodologias de ensino em diversas disciplinas. Trabalhando com alunos de escolas públicas localizadas próximas a manguezais, Rodrigues e Farrapeira (2008), também observaram que a realização de um estudo prático no ambiente proporcionou experiências significativas para o conhecimento, possibilitando uma nova leitura da realidade na qual estavam inseridos.

Também merece destaque nessa pesquisa o fato dos alunos aprenderem quais as principais causas que ameaçam o ecossistema, citando-as de forma clara e as maneiras de conservação dos manguezais. Os manguezais são de suma importância para as populações ribeirinhas e o conhecimento desse ecossistema serve de base para uma conscientização e conservação desse bem natural (PINHEIRO; TALAMONI, 2018). Os modelos de intervenção podem ser eficazes nesses processos e nada mais práticos do que realizar de forma dinâmica aulas que surjam efeitos e estimulem o diferencial e o potencial dos alunos.

Assim, as aulas de campo são aulas dinâmicas e bem mais centradas, tirando os educandos da zona de conforto e confrontando-os quanto aos conteúdos de maneira contextualizada. Disto isso, mostramos a importância da educação ambiental, buscando a conservação e preservação de ecossistemas ameaçados pela ação do 


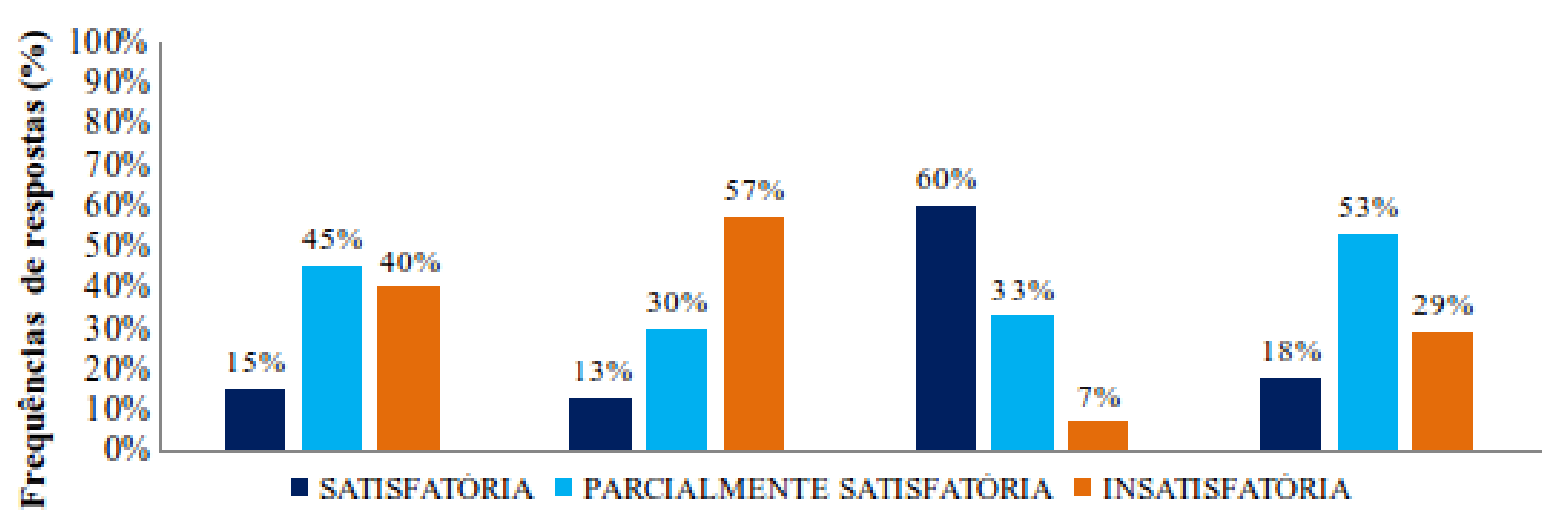

Figura 7: Frequência de respostas (\%) dos alunos, referente à pergunta 07: Quais os principais motivos que ameaçam os manguezais? Classificando-as quanto às categorias satisfatória, parcialmente satisfatória e insatisfatória, referente às ações efetivas que foram submetidos (questionário prévio, aula teórica e aula de campo).

Fonte: Autores.

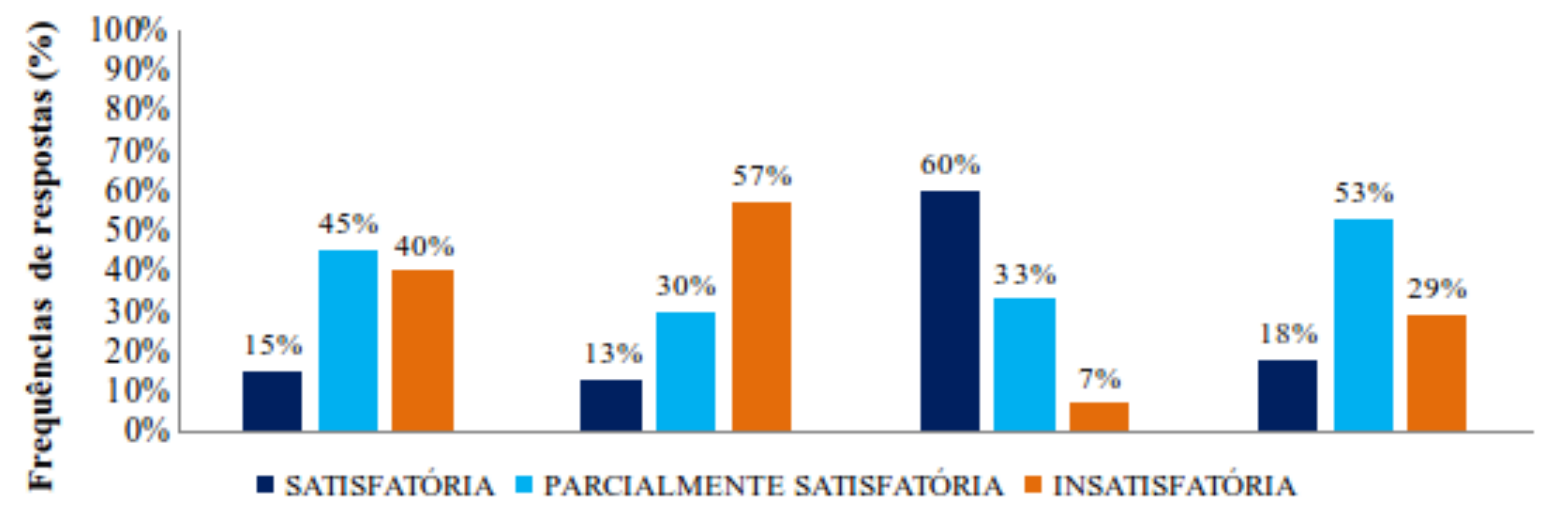

Figura 8: Frequência de respostas (\%) dos alunos, referente à pergunta 08: Você acha que o manguezal é importante? Justifique. Classificandoas quanto às categorias satisfatória, parcialmente satisfatória e insatisfatória, referente às ações efetivas que foram submetidos (questionário prévio, aula de campo e aula teórica).

Fonte: Autores. 
EFETIVIDADE DE AÇÕES PRÁTICAS DE EDUCAÇÃO AMBIENTAL PARA O ECOSSISTEMA MANGUEZAL NO ENSINO FUNDAMENTAL

homem, deixando as aulas mais didáticas e interativas.

\section{CONCLUSÕES}

Este estudo ao ser realizado constatou que os estudantes do ensino fundamental de Acaraú apresentam, no geral, conhecimento satisfatório a parcialmente satisfatório sobre os manguezais. Acredita-se que o fato dos alunos morarem perto deste ambiente e ter um conhecimento empírico, são os principais fatores responsáveis por esses resultados.

Com a proximidade da escola com os manguezais, seu conhecimento prévio reflete principalmente o conhecimento na utilização dos recursos existentes em prol da subsistência e a visão de um ambiente antropizado. Essa visão pode ser alterada com as estratégias de ensino, otimizada pela exposição visual sobre a biodiversidade do ambiente com a aula de campo e por meio de uma aula expositiva sobre as características e importância deste ecossistema. Assim, facilitando a aprendizagem significativa sobre o ecossistema manguezal e sua relevância, levando a mudanças conceituais na comunidade escolar e contribuindo para uma formação como agentes multiplicadores.

A efetividade de ações práticas aplicadas pelo presente trabalho é demonstrada pela aula de campo, pois esta atua como ponte para a saída da teoria tecnicista. Dessa forma, uma das sugestões propostas pelo presente trabalho é a educação ambiental mais prática, que pode ter um papel fundamental na sensibilização das pessoas no que diz respeito aos manguezais.

Contudo, é importante haver por parte dos docentes um novo olhar para essa temática, sendo necessário que os professores saiam do tradicionalismo da sala de aula e busquem outras formas para trabalhar, seja por meio de atividades de campo, elaborações de projetos dentre outros, sendo o aluno protagonista e crítico do seu proceso de aprendizagem.

\section{REFERÊNCIAS}

ACARAÚ. Lei Orgânica do Município de Acaraú. 2008. De 04 de julho de 2008.

ALBUQUERQUE, R. M. V. L. Estratégias para educação ambiental sobre o ecossistema manguezal na educação básica no município de Acaraú Ceará. Dissertação (Monografia) - Instituto Federal de Educação, Ciências e Tecnologia do Ceará, Ceará, 2016. 111f.

ALBUQUERQUE, R. M. V. L.; FARIAS, E. M. do N.; MAIA, R. C. Educação ambiental para o ecossistema manguezal: o papel dos pescadores artesanais.
Conexões-Ciência e Tecnologia, v. 9, n. 3, p. 41-51, 2015.

BRASIL. Regulamenta no âmbito federal, dispositivos da Lei $n^{0}$ 9.795, de 27 de abril de 1999, que dispõe sobre a educação ambiental, institui a Política Nacional de Educação Ambiental. Brasília, 1999. 27 de abril de 1999; $178^{\circ}$ da Independência e 111 da República.

Código Florestal (Lei no 12.651 de 2012), que reconhece o manguezal em toda a sua extensão como Área de Preservação Permanente (APP). Brasília, 2012.

DUKE, N. C. Mangrove floristics and biogeography revisited: further deductions from biodiversity hot spots, ancestral discontinuities, and common evolutionary processes. In: Mangrove Ecosystems: A Global Biogeographic Perspective. 1. ed. Australia: Springer, 2017. p. 17-53.

FARIAS, K. L.; ANDRADE, R. C. B. de. Educação ambiental: o manguezal no ensino fundamental. REMEA-Revista Eletrônica do Mestrado em Educação Ambiental, v. 25, n. 1, p. 1517-1256, 2010.

FARRAPEIRA, C. M. R.; PINTO, S. L. Práticas e metodologias do ensino de Zoologia. 1. ed. Recife: Universidade Federal Rural de Pernambuco, 2005. 48 p.

FRAGOSO, C. P. Dinâmica temporal do mercúrio na serapilheira do manguezal da foz do rio Paraíba do Sul, RJ. Dissertação (Monografia) - Universidade Estadual do Norte Fluminense Darcy Ribeiro - UENF. Campos Dos Goytacazes, Rio de Janeiro, 2011. $62 \mathrm{f}$.

\section{IBGE. INSTITUTO BRASILEIRO DE} GEOGRAFIA E ESTATÍSTICA. 2017. Disponível em: <https://cidades.ibge.gov.br/brasil/ce/acarau/ panorama> Acesso em: 07 jan. 2019.

\section{IPCE. INSTITUTO DE PESQUISA E} ESTRATÁGIA ECONOMICA DO CEARÁ.

2016. Disponível em: <http://www.ipece.ce.gov.br/ perfilbásicomunicipal/2016/Acarau.pdf> Acesso em: 07 jan. 2019.

JACOBI, P. R. Educação ambiental, cidadania e sustentabilidade. Cadernos de pesquisa, SciELO Brasil, v. 1, n. 118, p. 189-205, 2003.

LEE, S. Y.; PRIMAVERA, J. H.; DAHDOUHGUEBAS, F.; MCKEE, K.; BOSIRE, J. O.; CANNICCI, S.; DIELE, K.; FROMARD, F; 
EFETIVIDADE DE AÇÕES PRÁTICAS DE EDUCAÇÃO AMBIENTAL PARA O ECOSSISTEMA MANGUEZAL NO ENSINO FUNDAMENTAL

KOEDAM, N.; MARCHAND, C. et al. Ecological role and services of tropical mangrove ecosystems: a reassessment. Global Ecology and Biogeography, Wiley Online Library, v. 23, n. 7, p. 726-743, 2014.

LEãO, A. R.; PRATES, A. P. L.; MATTEO., F. Manguezal e as unidades de conservação: Atlas dos Manguezais do Brasil / Instituto Chico Mendes de Conservação da Biodiversidade. 1. ed. Brasília: Instituto Chico Mendes de Conservação da Biodiversidade, 2018.

MACHADO, I. F. A organização do trabalho pedagógico em uma escola do MST e a perspectiva de formação Omnilateral. 2003. 325f. Tese (Doutorado em Educação) - Tese (Doutorado)Faculdade de Educação, Universidade Estadual de Campinas ..., Campinas, 2003. $325 \mathrm{f}$.

MAIA, R. C. Manguezais do Ceará. 1. ed. Recife: Imprima, 2016.

MAIA, R. C.; COUTINHO, R. Structural characteristics of mangrove forests in brazilian estuaries: A comparative study. Revista de biología marina y oceanografía, Facultad de Ciencias del Mar, v. 47, n. 1, p. 87-98, 2012.

MARTINS, J. S. Situações Práticas de Ensino e aprendizagem significativa. 1. ed. Campinas: Autores Associados, 2009.

PAULA, A. L. d. S.; LIMA, B. K. d. S.; MAIA, R. C. The recovery of a degraded mangrove in ceará through the production of laguncularia racemosa (1.) cf gaertn.(combretaceae) and avicennia sp. stapf ex ridl (acanthaceae) seedlings. Revista Árvore, SciELO Brasil, v. 40, n. 3, p. 377-385, 2016.

PINHEIRO, M. A. A.; TALAMONI, A. C. B. Educação Ambiental sobre Manguezais. 1. ed. São Vicente: Campus do Litoral Paulista - Instituto de Biociências, 2018.

REZENDE, C. E.; KAHN, J. R.; PASSARELI, L.; VÁSQUEZ, W. F. An economic valuation of mangrove restoration in brazil. Ecological Economics, Elsevier, v. 120, n. 1, p. 296-302, 2015.

RODRIGUES, L. L.; FARRAPEIRA, C. M. R. Percepção e educação ambiental sobre o ecossistema manguezal incrementando as disciplinas de ciências e biologia em escola pública do recife-pe. Investigações em Ensino de Ciências, v. 13, n. 1, p. 79-93, 2008.
SATO, M.; SANTOS, J. E. Um breve itinerário pela educação ambiental. In: da Educação Ambiental à Esperança de Pandora. Brasil: Ribas, 2001. p. 1-10.

SCHAEFFER-NOVELLI, Y. Grupo de ecossistemas: Manguezal, Marisma e apicum. ANP (Agência Nacional do Petróleo) Brasil Round 5. 2012. Disponível em: <http://www.anp.gov.br/brnd/round5/ .../manguezal_marisma_apicum.pdf $>$. Acesso em: 12 dez. 2012.

SOUSA, M. E. O Litoral extremo oeste do ceará e a cidade de Acaraú na busca do turismo e do desenvolvimento socioeconômico. Dissertação (Mestrado Profissional em Gestão de Negócios Turísticos) - Centro de Estudos Sociais Aplicados, Universidade Estadual Do Ceará, Fortaleza, 2017.

SOUZA, K. N. S. Resíduos sólidos em manguezais no Ceará: o uso da estrutura vegetal dos bosques para o monitoramento ambiental. Dissertação (Pós-Graduação em Tecnologia e Gestão Ambiental) - Instituto Federal de Educação, Ciências e Tecnologia do Ceará, Fortaleza, 2016.

THIERS, P. R. L.; MEIRELES, A. J. A.; SANTOS, J. E. O. Manguezais na costa oeste cearense preservação permeada de meias verdades. 1 . ed. Fortaleza: Editora Imprensa Universitária, 2016.

TOMLINSON, P. B. The botany of mangroves. 2. ed. Cambridge: University Press Cambridge, 2016.

VAIRO, A. C.; Rezende Filho, L. A. Concepções de alunos do ensino fundamental sobre ecossistemas de manguezal: o caso de um colégio público do rio de janeiro. Ensino, Saude e Ambiente, v. 3, n. 2, p. 15-19, 2010.

VALE, C. C.; SCHAEER-NOVELLI, Y. A Zona Costeira do Brasil e os manguezais: Atlas dos Manguezais do Brasil / Instituto Chico Mendes de Conservação da Biodiversidade. 1. ed. Brasília: Instituto Chico Mendes de Conservação da Biodiversidade, 2018. 